\title{
Parto con Espátulas Colombianas
}

\author{
Dr. Ditlev Fossen
}

El presente artículo describe las espátulas colombianas, que constituyen una alternativa al extractor por vacío y los forceps tradicionales, cuando la cabeza fetal ya ha avanzado hasta el suelo pélvico. Con base en la experiencia de 144 extracciones, se considera que las espátulas son un instrumento eficaz $y$ relativamente innocuo, inciuso en manos inexpertas. Después de haber sido utilizadas durante dos años en el Departamento Gineco-Obstétrico del Hospital de Sarpsborg (Noruega), las espátulas han desplazado al extractor por vacío como el instrumento preferido en la aplicación instrumental baja.

Según Das (2), los forceps se pueden dividir en cuatro categorías, basadas en la relación de las ramas u hojas entre sí. Estas pueden estar cruzadas formando una $X$, o divergentes como una $V$; paralelas o convergentes.

La mayoría de los tipos de forceps utilizados en la actualidad derivan del forceps original de Peter Chamberlain (aprox. 1660) y del tipo cruzado con cierre hacia la parte media. Los forceps convergentes han dejado de emplearse.

En 1968, Laufe (4) introdujo una versión moderna de forceps divergente

Departamento Gineco-Obstétrico Hospital de Sarpsborg (Noruega) "Tidsskrift for Den norske laegeforeningen" $\mathrm{Nr}$. 8, 1982.

Versión en español: Margarita Sjõberg de Zea. Bogotá, julio 8 de 1982.
(Fig. 1). En este forceps, las hojas emergen de un cierre, lo cual les permite divergir. El primer forceps paralelo lo ideó Palfyn en 1720. Primero utilizó tracción en cada hoja por separado, pero posteriormente amarró las dos hojas con una tira de tela, con lo que el instrumento ya no era verdaderamente paralelo.

Un ejemplo moderno del instrumento paralelo lo constituyen las Ilamadas cucharas o espátulas de Velasco-Chiriboga, empleadas en Colombia desde 1974. En los últimos años el uso del instrumento se ha extendido a diferentes países suramericanos y también se emplea en varios hospitales de importancia en la Alemania Federal. Hasta ahora sólo había literatura disponible proveniente de Colombia sobre el instrumento.

\section{Figura 1}

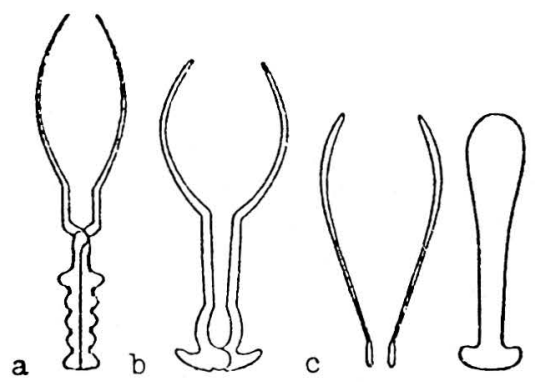

a) Forceps cruzado (Simpson)

b) Forceps divergente (Laufe)

c) Espátulas colombianas, vista superior y lateral. 


\section{DESCRIPCION DEL INSTRUMENTO}

Las espátulas tienen $25 \mathrm{~cm}$ de longitud. No tienen curvatura pélvica y sus bordes exteriores son simétricos. La curvatura cefálica tiene un radio amplio y es más prominente en la parte de la cara donde hay una leve hendidura. La parte más angosta de la espátula termina en un mango transversal de $6 \mathrm{~cm}$ de ancho.

\section{INDICACIONES Y USO}

Las indicaciones y uso del instrumento son lo mismo que para forceps comunes, pero su uso no se considera conveniente cuando la cabeza fetal se encuentra a un nivel superior a $2 \mathrm{~cm}$ por debajo de las espinas ciáticas.

El instrumento debe emplearse preferiblemente en la aplicación baja, es decir, cuando la cabeza fetal se encuentra sobre el suelo pélvico.

\section{PREPARACION Y TECNICA}

El parto con espátulas se puede efectuar mediante bloqueo del nervio pudendo, con anestesia local como suplemento. En los casos en que la cabeza se alcanza a ver por la vulva suele ser suficiente la anestesia local en el perineo. Para facilitar la introducción de las espátulas, que distienden bastante la vulva, y para disminuir la resistencia de las partes blandas durante la extracción, se debe practicar episotomía con fines profilácticos. Las espátulas se introducen en la vagina en la misma forma que los forceps convencionales pero, puesto que las espátulas no tienen ninguna conexión entre sí, da lo mismo por cual lado se inicia la aplicación.

Las espátulas deben colocarse biparietalmente y sus extremos llegar hasta el borde inferior de las mandíbulas. La extracción se efectúa jalando de los mangos transversales. Cuando es necesario hacer una tracción relativamente fuerte, los mangos deben mantenerse a una distancia de aproximadamente dos dedos de ancho (Fig. 2).

Figura 2, a y b
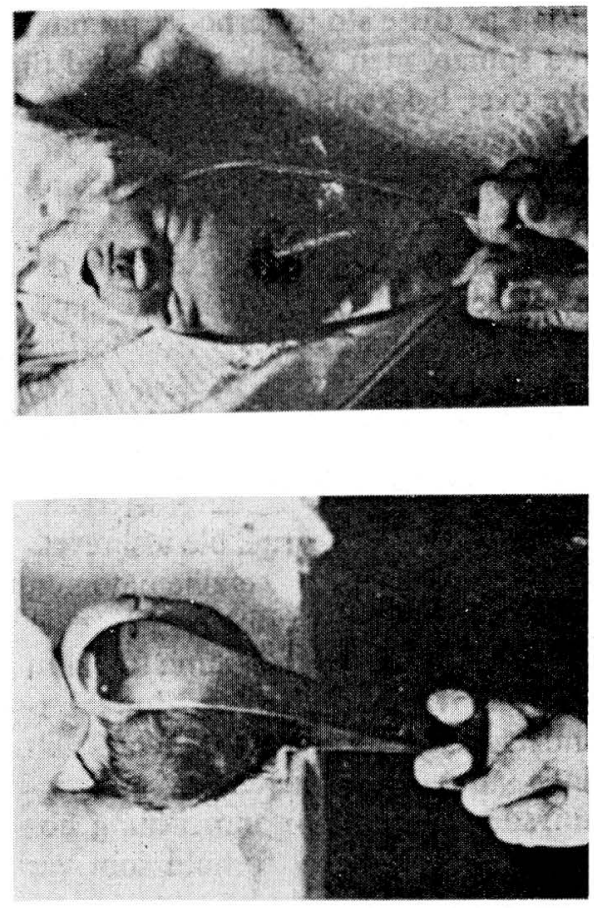

Extracción por espátulas

a) con las dos manos

b) con una sola mano

En la mayoría de los casos, la cabeza de un feto en posición baja sale con una suave tracción o con varios tirones suaves sucesivos. En este caso, los mangos pueden mantenerse unidos entre los dedos índice y medio de una mano. La extracción debe efectuarse en forma sincronizada y lenta y la fuerza se aplica, al igual que en la extracción por vacío o por forceps, periódicamente. 
Las espátulas tienden a separarse durante la extracción, pero encuentran resistencia en las partes blandas y la pelvis, lo cual hace que se mantengan en su lugar contra la cabeza fetal. Por lo tanto, no es necesario ejercer presión sobre las hojas de las espátulas. Esto podría interferir con la movilidad de las mismas y resultar en compresión directa sobre la cabeza fetal. Las espátulas se retiran cuando la cabeza se acerca a la incisión; eventualmente se puede dejar una para facilitar la salida de la cabeza.

Las espátulas se pueden utilizar para rotación. Según el inventor, la rotación se efectúa más fácilmente durante un pujo y con una sola espátula, a la vez que se ejerce presión contra un lado de la cabeza del feto.

\section{MATERIAL Y RESULTADOS}

Nuestra experiencia clínica se basa en 144 extracciones, de las cuales la tercera parte se llevó a cabo en el Departamento Gineco-Obstétrico del Hospital de Aker y el resto en el Departamento GinecoObstétrico del Hospital de Sarpsborg.

Más de la mitad de las extracciones fue ejecutada por colegas que nunca habían utilizado forceps convencionales. El $80 \%$ de las parturientas eran primíparas.

Las indicaciones para parto instrumental, las formas de anestesia y las complicaciones maternas se presentan en la Tabla 1.

La cabeza fetal había llegado hasta el suelo pélvico en 108 mujeres, al aplicarse las espátulas. En 28 casos, la cabeza estaba situada aproximadamente a $2 \mathrm{~cm}$ por debajo del nivel de las espinas. Ocho historias clínicas carecen de datos acerca del descenso de la cabeza por el canal de parto. De 24 fetos en posición occipital posterior fueron rotados 8 . Se presentó detención transversa profunda en 5 casos, de los cuales 3 fueron rotados con una sola espátula y los restantes con ambas. El grupo con posición craneana anormal representó 5 de los 8 casos registrados de lesión esfinteriana.

Tabla No. 1

INDICACIONES, FORMAS DE ANESTESIA $Y$ COMPLICACIONES

MATERNAS EN 144 EXTRACCIONES CON ESPATULAS

\begin{tabular}{|lr|}
\hline Indicaciones & Número \\
\hline Parto lento & 83 \\
Amenaza de asfixia & 55 \\
Otras & 6 \\
& \\
Anestesias & \\
Bloqueo del nervio pudendo & 109 \\
Epidural & 4 \\
Anestesia local & 26 \\
No hay datos & 5 \\
& \\
Complicaciones maternas & \\
Ruptura total del esfinter & 1 \\
Ruptura parcial del esfinter & 7 \\
Desgarramiento extenso de vagina & 9 \\
Desgarramiento del cuello uterino & 1 \\
\hline
\end{tabular}

En 7 de las mujeres el parto se finalizó con las espátulas, después de que la extracción por vacío había fracasado. En 3 de estos casos la cabeza fetal se encontraba primero a la altura de las espinas, pero había alcanzado a bajar hasta un poco más arriba del suelo pélvico antes de que se zafara la campana de succión.

Con excepción de un caso de muerte fetal intrauterina debida a hidrocefalia y malformaciones extensas, no hubo mortalidad perinatal en el presente ma- 
terial. Uno de los niños presentó marcas relativamente profundas en los pómulos causadas por las espátulas, después del parto. En este caso, la cabeza estaba situada en posición occipital posterior y relativamente alta. Las marcas habían desaparecido cuando se le dio de alta.

No se presentaron desgarramientos cutáneos, hematomas cefálicos, fracturas craneanas, paresias faciales o signos de hemorragia intracraneana en ninguno de los niños. El exámen efectuado por el pediatra a más tardar un día después del parto y el día de salida no dio lugar a observaciones en ninguno de los niños, a excepción de condiciones que no tenían ninguna relación con el parto o la indicación del parto.

\section{DISCUSION}

La aplicación de las espátulas resulta más sencilla cuando la cabeza ha terminado de rotar y se encuentra sobre el suelo pélvico. Cuando la cabeza esta situada a más altura no siempre es tan fácil colocar las espátulas en su sitio. Esto se debe a que son cortas, que carecen de curvatura pélvica y que además provocan desgarramientos en las partes blandas a la salida de la pelvis. En estos casos, la mayoría de las personas familiarizadas con los forceps los prefieren a las espátulas.

En la mayoría de los casos, en los cuales el parto vaginal por instrumento es de actualidad, se trata de aplicación baja y es aquí donde las espátulas constituyen un instrumento muy eficaz $y$ de fácil manejo que, especialmente en manos inexpertas, ofrece ciertas ventajas sobre el forceps cruzado.

Al igual que el forceps divergente, las espátulas pueden adaptarse a todos los tamaños de las cabezas a diferente grado de divergencia. Durante la extracción, la presión se concentra en la cara, en tanto que la presión sobre el cráneo probablemente no sobrepasa la ejercida por la resistencia en el conducto de parto.

Por su mecanismo de acción las espátulas no tienen el componente de compresión externa que se presenta con el forceps cruzado cuando se presionan los mangos y la fuerza empleada se traslada a las hojas del mismo. Cuando los forceps se aplican incorrectamente, dicha compresión puede tener consecuencias graves. En estudios teóricos y controlados, Laufe (5) ha demostrado que la compresión sobre la cabeza fetal se puede reducir significativamente, usando forceps divergentes, en vez de forceps cruzados. Las espátulas también funcionan como un instrumento divergente. Por lo tanto, los resultados de Laufe respaldan la teoría de que hay menos compresión cuando se usan las espátulas. Hasta ahora no se ha esclarecido si la menor compresión puede tener algún significado clínico en los partos sin otras complicaciones (5).

Las espátulas se mantienen en su sitio contra la cabeza fetal por las paredes del canal de parto. Por lo tanto, hay menos necesidad de efectuar rotación activa durante la extracción por espátulas, que por forceps. Al igual que en la extracción por vacío, la rotación frecuentemente se presenta en forma espontánea mientras se efectúa la tracción. Cuando las espátulas no han sido colocadas en forma correcta, existe un riesgo no despreciable de lesión en la cabeza fetal. En el material de Colombia (6), que abarca 756 extracciones, no se observó ninguna lesión craneana grave, al igual que en nuestro material.

El profesor Erich Saling indica, en un informe personal, que en su clínica en Berlín, donde el instrumento ha sido usado ampliamente desde 1976, no se han observado.lesiones craneanas, aparte de algunas excoriaciones menores, ni 
siquiera cuando un novato ha colocado una de las espátulas sobre la cara del feto. Un tirón demasiado violento puede dar como resultado que las espátulas se safen, impidiendo de antemano cualquier tentativa de hacer pasar la cabeza por un conducto cervical muy estrecho donde es necesario utilizar bastante fuerza. En nuestro Departamento no se ha presentado hasta ahora el caso de que las espátulas se hayan zafado.

Cuando es necesaria la rotación activa se pueden sujetar ambas hojas de las espátulas. Sin embargo, frecuentemente ha sido posible efectuar la rotación con ayuda de una sola espátula, después de lo cual la cabeza ha seguido espontáneamente. Velasco-Chiriboga sostiene que el instrumento ocasiona menos lesiones en las partes blandas de la madre que el forceps convencional (7). A juicio de nuestra propia experiencia, la incidencia de dichas lesiones probablemente es igual con ambos tipos de instrumento.

En el transcurso de los últimos años, en nuestro Departamento, al igual que en muchos otros departamentos obstétricos en nuestro país, sólo excepcionalmente hemos utilizado la extracción por forceps. La extracción por vacío se ha empleado preferencialmente, entre otras razones porque es más fácil de aprender y frecuentemente resulta más sencillo que el uso de forceps. La mayoría de los obstétras de Europa Septentrional y Occidental opinan además que el extractor por vacío es un instrumento menos peligroso que los forceps, especialmente en manos inexpertas $(1,3)$.

No obstante, el extractor por vacío resulta inadecuado en los casos de ciertas posiciones craneanas anormales, y un grave inconveniente de este instrumento es que es necesario esperar 6-8 minutos antes de que la campana se encuentre firmemente adherida a la cabeza fetal y la extracción pueda iniciarse. Esto puede representar un tiempo valioso que el operador experimentado no tiene que perder durante una extracción sencilla por forceps.

Con las espátulas colombianas se aprovechan las ventajas del principio de los forceps, a la vez que la aplicación del instrumento es mucho más sencilla. El riesgo de lesiones en la cabeza fetal es mínimo, incluso en manos inexpertas. Durante los dos años en que las espátulas han sido utilizadas en el Departamento Gineco-Obstétrico del Hospital de Sarpsborg, han desplazado al extractor por vacío como el instrumento de uso preferido.

Desde el 1-IV de 1980 hasta el 31III de 1981, cincuenta y nueve partos $(6.3 \%)$ fueron terminados con las espátulas, veintidos $(2.3 \%)$ con extractor por vacío y $5(0.5 \%)$ con forceps de Simpson. En la actualidad, el extractor por vacío sólo se emplea cuando la cabeza fetal está situado más arriba del suelo pélvico. El uso más extendido de las espátulas mostrará si se justifica que se conviertan en el instrumento de primera línea para las extracciones bajas.

\section{RESUMEN}

El artículo describe las espátulas de Velasco-Chiriboga, una alternativa para el forceps y el extractor de vacío en la terminación del parto, cuando la presentación ha descendido al piso pélvico. Para evaluar su seguridad en la madre y el recién nacido se analizan 144 partos en los cuales se empleó el instrumento, demostrando ser eficaz, relativamente inocuo, aplicable rápida y fácilmente incluso por personas de poca experiencia. Durante los dos años en que han sido empleadas en nuestro departamento han desplazado al extractor de vacío como instrumento preferido para extracciones bajas. 


\section{OPERATIVE VAGINAL DELIVERY WITH VELASCO SPATULAS}

\section{SUMMARY}

D. Fossen, MD

The article describes Velasco-Chiribogas spatulas which can be used as an alternative to forceps and to vacuum extractors for termination of labour when the level of the head is low.

In order to evaluate their safety for mother and child, 144 deliveries with the instrument were analysed.
The spatulas proved to be an efficient and relatively innocuous instrument which can be applied rapidly and easily sven by those who are less skilled.

During the 2 years the spatulas have been in use at our department, they have enjoyed increasing popularity, and today they have replaced the vacuum extractor as the preferred instrument for outlet deliveries. 